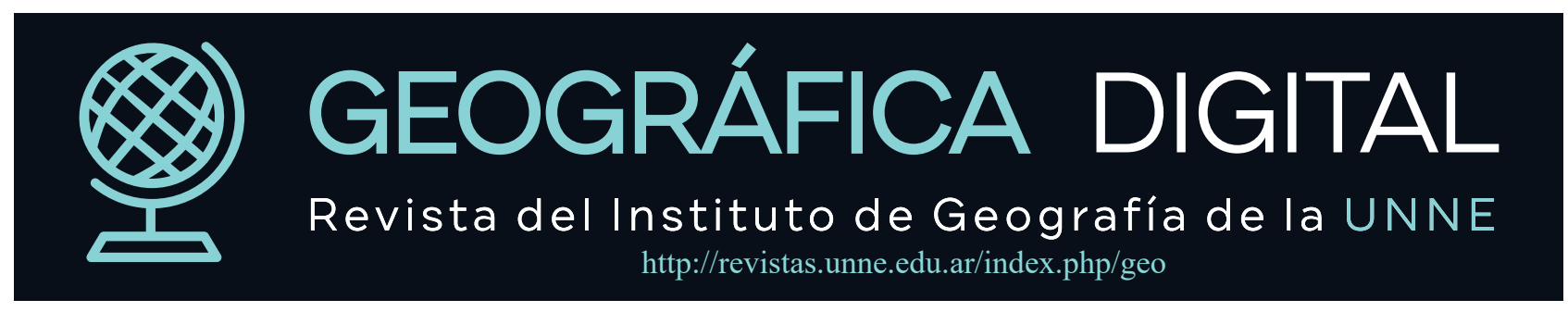

Revista Geográfica Digital, 2021, Vol. 18, No 35, 127-137 pp., E-ISSN: 1668-5180: DOI: http://dx.doi.org/10.30972/geo.18355138

\title{
El espacio geomorfológico de Bella Vista modificado por efecto de obras de descarga
}

\section{Bella Vista geomorphologic space modified by the effects of download works}

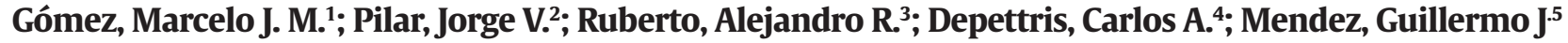 \\ 1Grupo de Investigación del Dpto. de Hidráulica, Facultad Ingeniería, Universidad Nacional de Nordeste. mgichaco@yahoo.com.ar \\ 2Grupo de Investigación del Dpto. de Hidráulica, Facultad Ingeniería, Universidad Nacional de Nordeste. jvpilar@gmail.com \\ 3Grupo de Investigación del Dpto. de Hidráulica, Facultad Ingeniería, Universidad Nacional de Nordeste. aleruberto44@yahoo.com.ar \\ 4Grupo de Investigación del Dpto. de Hidráulica, Facultad Ingeniería, Universidad Nacional de Nordeste. cdepettris@ing.unne.edu.ar \\ 5Grupo de Investigación del Dpto. de Hidráulica, Facultad Ingeniería, Universidad Nacional de Nordeste. guillemendez79@gmail.com
}

\section{Palabras Claves:}

Erosión hídrica

Bella Vista

Mitigación

Geomorfología

Sistema hidrológico

Keywords:

Water erosion

Bella Vista

Mitigation

Geomorphology

Hydrologic System.

Recibido: 22/12/2020

Aceptado: 07/05/2021

\section{R E S U M E N}

En el presente trabajo se realiza una descripción sobre la geomorfología, con atención en el sistema hidrológico de la localidad de Bella Vista en la provincia de Corrientes, ubicada entre el río Paraná y la ruta provincial $n^{\circ} 27$, que condiciona la expansión de la trama urbana, debiendo ésta crecer progresivamente hacia el sur.

Su área urbana está localizada a una altura de 67 m.s.n.m. (IGN) promedio presentando un desnivel de 25 a 30 metros con el río, formando barrancas cuyo relieve irregular es consecuencia del tipo de suelo susceptible a la erosión hídrica, lo que ocasiona pérdida de grandes fracciones de terrenos.

Nuevos asentamientos urbanos y la concentración de población en sectores consolidados con alta densidad poblacional y con aumento de la impermeabilización del terreno que genera un mayor volumen de escurrimiento directo, con consecuencia en las salidas a los cuerpos de agua receptores.

Se analiza la geomorfología del lugar, identificando la formación de cárcavas en el ejido urbano y el efecto retrogradante de estas que comprometen la estabilidad de las estructuras.

Se evalúan las acciones de mitigación de efectos tomando como referencia estudios y proyectos de desagües pluviales y cloacales de los años 1997, 1999, 2012 y 2015.

\section{A B S T R A C T}

In the present work a description of the geomorphology, with special attention on the hydrologic system of Bella Vista town at Corrientes Province, located between Paraná River and the provincial route № 27, which determines the expansion of the urban plot, making it to grow progressively to the south.

Its urban area is located at an altitude of 67 meters above sea level (IGN) presenting an unevenness of 25 to 30 meters with the river, forming canyons which irregular relief is a consequence of the soil type that is susceptible to water erosion, and produces the lost of large fractions of land.

New urban settlements and the population concentration at consolidated areas with a high population density and an increment of the land imperviousness generates a higher direct runoff volume with consequences at the outlets to the water bodies receivers.

The geomorphology of the place is analyzed, identifying the formation of gullies in urban areas and their backsliding effect which compromise the stability of structures.

Actions of effects mitigation are evaluated taking as a reference studies and projects of storm and sewer drains of the following years: 1997, 1999, 2012 and 2015 


\section{Introducción}

La localidad de Bella Vista en la provincia de Corrientes se ubica sobre la ruta provincial $n^{\circ} 27$ (Figura 1), constituyendo un punto de intercambio de bienes y personas de numerosos centros urbanos próximos y de diferentes jerarquías. Representa para su área de influencia un centro de servicios debido a que cuenta con una adecuada organización y equipamiento urbano en cuanto a educación salud y recreación, e instalaciones de producción, comercios y servicios entre otros.

Figura 1. Ubicación geográfica.

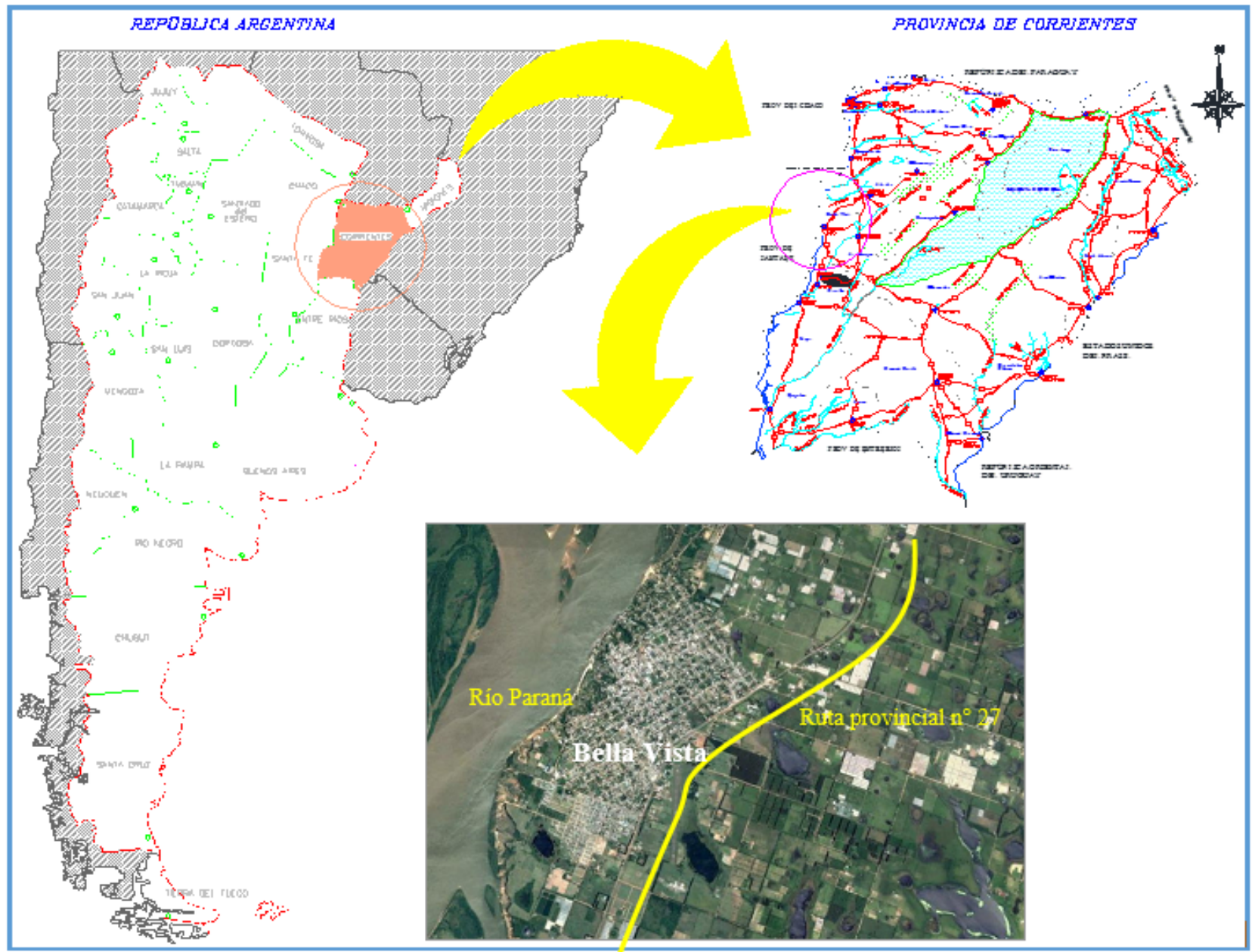

Fuente: elaboración propia

El área urbana de la citada localidad está emplazada sobre la margen izquierda del río Paraná, con una altura de 67 m.s.n.m. (IGN) presentando un desnivel que varía entre 25 a 30 metros, con el río, formando de esta forma barrancas o acantilados, cuyo relieve irregular es consecuencia del tipo de suelo susceptible a erosión hídrica, que ocasiona pérdida de fracciones de terrenos y hasta manzanas enteras, que según datos catastrales existieron, pero en la actualidad ya no existen físicamente, retrocediendo el límite de las barrancas hacia el interior de la planta urbana, formando cárcavas profundas o zanjones.

Así además en el interior de la planta urbanizada pueden observarse la existencia de depresiones inundables y lagunas que restringen el uso y ocupación de amplias zonas en el entorno de las mismas.

El emplazamiento de la trama urbana entre el río Paraná y la ruta provincial № 27, ha condicionado la expansión y crecimiento urbano, adaptándose la configuración a esta zona.

La problemática hídrica de la localidad de Bella Vista está asociada a dos aspectos: 1) los efectos producidos por la acción dinámica del escurrimiento del rio Paraná sobre sus orillas (no abordado en este trabajo); 2) los efectos procedentes de la situación de descargas de desagües pluviales y otras obras de descargas (cloacales) y de las cárcavas existentes.

Los desagües pluviales pueden ser considerados bajo dos aspectos diferentes. Por un lado, la distribución, su capacidad evacuadora respecto de los aportes que recibe y, fundamentalmente, la limitada red natural existente frente a las condiciones impuestas por el medio físico de la ciudad. Por otro lado, 
las condiciones de su descarga al río, la que necesariamente va ligada a la existencia de las cárcavas que se constituyen en profundos zanjones que penetran en la planta urbana, motivo por el cual los conductos permanentemente son afectados por la erosión retrógrada que se produce en su salida al río considerado como colector principal.

Las cárcavas existentes (Figura 2) en pleno centro de la localidad, constituyen un problema, no solo por la pérdida de espacio e inconvenientes que ocasionan a los conductos de desagües que en ellas descargan, sino también porque a la vez se transforman en áreas receptoras de todo tipo de descarga y su avance paulatino va comprometiendo la estabilidad de las estructuras cercanas a ellas. La cárcava que se indica, activa y controlada mediante medidas de atenuación ejecutadas en las inmediaciones, que consisten entre otras en un empastado desmalezado periódicamente; las especies que se utilizan tienen una cobertura densa, preferiblemente de tipo rizomatosa; evitando aquellas de tipo cespitosas o que constituyan matas aisladas. Se emplean también cortinas vegetales también como una estrategia recomendada, en razón que el viento suele provocar voladuras, que luego provocan correderas del agua; como precaución adicional es preciso que en el área de influencia de la cárcava no existan prácticas culturales (explotaciones agrícolas y/o desagües) que provocan eventuales correderas o incrementan los volúmenes de descarga en la cárcava.

Figura 2. Ubicación de cárcava en la localidad de Bella Vista.

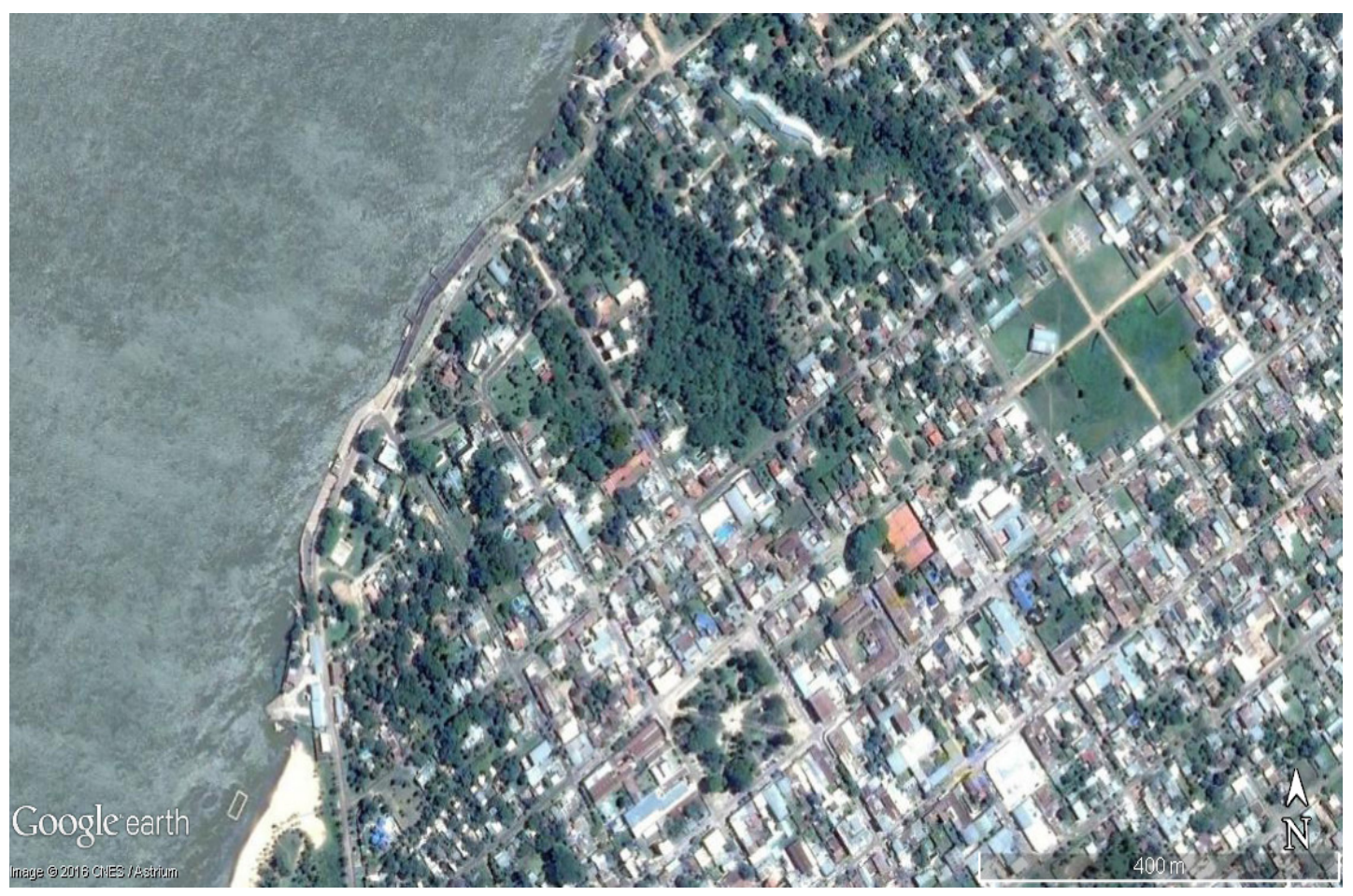

Fuente: Google Earth.2013.

Puntualmente, en el caso de los conductos pluviales la erosión va descalzando el apoyo de los mismos, generando desplazamientos y desprendimiento de los caños, aumentando de esta forma las perturbaciones en el escurrimiento en la zona de descarga al río, lo que acelera el proceso erosivo en el área circunscripta por la cárcava propiamente dicha.

Concretamente, en la salida de los conductos, el agua al caer, erosiona el piso, y como este piso está constituido por suelo altamente erosionable, los canales por donde circula el agua hasta el río, van cambiando de posición. Por lo general lo hace recostándose al pie de las barrancas, el que una vez erosionado origina el deslizamiento de las mismas.

En este trabajo se busca describir sucintamente las características geomorfológicas de la localidad de Bella Vista en la provincia de Corrientes, con atención en el subsistema hidrológico donde las corrientes de agua modelan la superficie formando sistemas naturales de desagües, con erosión y transporte de material.

Conocer en el espacio, analizado la vulnerabilidad del mismo, identificando los tipos de suelos susceptibles a erosión hídrica.

Analizar la influencia de obras civiles como de desagües pluviales artificiales y otro tipo de obras de descargas (desagües cloacales), cómo estas ejercen acciones que impactan sobre el sistema geomorfológico. 
Evaluar acciones y medidas de mitigación propuestas y aplicadas al ambiente antrópico.

\section{2. Área de estudio}

La Provincia de Corrientes, ubicada en el nordeste argentino el paralelo $-27^{\circ}$ y $30^{\circ}$ de latitud sur y los meridianos $55^{\circ}$ y $59^{\circ}$ de longitud oeste, está localizada (Figura 1) en el centro de la región Mesopotámica de Argentina, con una superficie de $88.199 \mathrm{~km}^{2}$, equivalente al 3,2\% del territorio nacional.

Es una provincia con fronteras internacionales separadas por dos grandes colectores de la Cuenca del Plata: el río Uruguay al este, lindando con Brasil y Uruguay; el río Paraná al norte limítrofe con Paraguay, y el mismo río Paraná en su tramo argentino por el oeste, limítrofe con las provincias de Chaco y Santa Fe; al sur los río Guayquiraró y Mocoretá, la deslindan de la provincia de Entre Ríos.

La localidad de Bella Vista, cabecera del Departamento del mismo nombre, está localizada en el centro-oeste de la provincia de Corrientes, sobre margen izquierda del Río Paraná.

El área de estudio involucrado en el presente trabajo abarcará solamente el sector correspondiente al ejido urbano de la localidad de Bella Vista, donde se evidencia claramente una rápida erosión de su orilla por medios antrópicos.

\section{Materiales y métodos}

Como sistema el ciclo hidrológico se puede representar como tal, como una estructura o volumen en el espacio, delimitada por una frontera, cuyos componentes internos interactúan entre sí o con otros sistemas adyacentes (Chow et al., 1994).

Una vez eliminada todas las intercepciones iniciales (retenidas en la vegetación), el volumen restante se transformará en escurrimiento sobre la superficie del terreno, el cual a su vez llegará al sistema de drenaje del área de captación para formar el escurrimiento superficial (Breña y Jacobo, 2006); parte de estos escurrimientos saldrán del subsistema como infiltración al subsistema subterráneo o bien como escurrimiento por medio de los sistemas de drenaje regionales, desplazándose a niveles más bajo progresivamente, y que finalmente llegan al océano.

La escorrentía llega a ordenarse en un sistema de desagües con áreas más o menos piriformes, limitadas por las líneas divisorias (Strahler, 1974), y dentro de esta área redes ramificadas de cauces para disponer eficientemente las aguas de escorrentía y de este modo erosionar progresivamente las superficies del terreno hasta denudarlo.

También Strahler menciona que un sistema de desagüe es un mecanismo de convergencia, con escorrentías débiles y difusas al inicio hasta originar cursos con actividad progresivamente más intensa.

El estudio de los sistemas de desagüe se aborda relacionando la hidrología y la geología, donde las corrientes de agua erosionan y transportan material modelando los sistemas naturales de desagües.

La Geomorfología es la ciencia que estudia las formas del relieve terrestre, como resultado de la interacción entre las rocas y estructuras y los medios bioclimáticos, a través del tiempo (Popolizio, 1973).

Este sistema geomorfológico tiene componentes o subsistemas que lo componen, a saber: 1) Litoestructural; 2) Hidrológico; 3) Biótico y 4) Edáfico.

Todos estos componentes están en equilibrio, en forma totalmente natural, adaptándose a modificaciones naturales permanentemente, pero el comportamiento del sistema tiene capacidad de reaccionar frente estímulos externos, adoptando luego de un cierto tiempo, un equilibrio dinámico, oscilante dentro de un umbral de indiferencia.

Cuando ese umbral es superado, según Popolizio, los problemas de las obras civiles (medio antrópico) que se presentan, son frecuentemente consecuencia de haber excitado el sistema por arriba del umbral de irreversibilidad y no prever el nivel probable de equilibrio.

La erosión acelerada del suelo se da al ejercer una fuerza directa de las gotas de agua que caen (erosión por salpicadura) y una fuerza de arrastre sobre la superficie del suelo que arranca material del mismo.

Esta remoción de suelo bajo condiciones naturales estables relativamente lenta es parte del proceso natural de denudación. 
Esta lenta remoción de suelo se contrasta enormemente con la situación de erosión acelerada del suelo producida por medios antrópicos, donde interviene el hombre con sus actividades, provocando erosión con mayor velocidad, la que transporta el suelo a un ritmo mucho más rápido. Esta acción se intensifica y/u origina cuando se modifican las condiciones de cobertura vegetal o se modifica la superficie del terreno o ambas situaciones en simultáneo.

El retiro de la cobertura vegetal expone al suelo directamente a la acción degradante que producen, primero las gotas de lluvia que caen y después el escurrimiento generado que arrastra el material del suelo. La impermeabilización del suelo, por efecto de las construcciones asentadas sobre el mismo, genera un mayor volumen de escurrimiento.

La erosión y sobre todo la erosión acelerada influyen en el modelado de las estructuras dando lugar a nuevas formas topográficas.

Las orillas de la localidad de Bella Vista son elevadas con respecto al nivel del río Paraná, y además por el tipo de suelo son vulnerables a la erosión hídrica (Figura 3).

Para abordar el análisis y diagnóstico de la problemática que se estudia se describe la zona de estudio (geomorfológica), con análisis de diferentes proyectos ejecutados y otros a ejecutar con afectación al sistema geomorfológico:

\subsection{El medio natural}

Bella Vista se encuentra en una unidad geomorfológica definida con criterio taxonómico como lomas y planicies embutidas y el valle del río Paraná (Popolizio, 1977; Bruniard, 1997; Serra, 2001).

La formación geológica que se manifiesta en el oeste de Corrientes corresponde al Lujanense y el platense encajados en terrazas altas por ascenso de los bloques positivos y de la Mesopotamia en el cuartario. Esto se pone de manifiesto por la formación de cárcavas, donde las aguas de lluvia al caer y escurrir producen una acción retrogradante.

Según indica Torres en 1954 en las perforaciones realizadas por Obras Sanitarias de la Nación se ha observado una sucesión de sedimentos areno-arcillosos rojizos, descansando sobre arenas amarillentas de la serie Mesopotamiense.

El mapa geológico de la provincia de Corrientes reproducido en la plancha $\mathrm{n}^{\circ} 7$ por (Bruniard, 1997) muestra las diversas formaciones geológicas de la provincia hecha por Herbst y Santa Cruz en 1996. Para la zona de estudio indica que corresponde a la formación Toropí y Yupoi correspondiente al pleistoceno superior.

La provincia de Corrientes si bien se caracteriza por ser una llanura de baja energía de relieve, presenta procesos activos de erosión de suelos. Las causas vinculadas a estos procesos implican la integralidad de una serie de factores como: las propiedades físicas y químicas de la capa superficial (arable), la topografía, la posición en el paisaje y el drenaje. Además del factor climático vinculado a la intensidad de las lluvias y la intensidad y dirección de los vientos dominantes. Por lo tanto, el deterioro por erosión, tanto hídrica como eólica, se puede atenuar o exacerbar bajo el uso antrópico, según las prácticas de manejo utilizadas y la cobertura del suelo (Ligier et al, 2015). Es importante por lo tanto conocer aquellas zonas de la provincia con los mayores riesgos potenciales y el estado actual del recurso suelo.

\subsection{Clima}

Las condiciones climáticas son bastante homogéneas a lo largo de la provincia, ya que no existen obstáculos para el desplazamiento de las masas de aire. Se tiene una temperatura media de $23^{\circ} \mathrm{C}$ y una precipitación de $1.200 \mathrm{~mm}$ anuales. No existen estaciones secas ni, en general, sequías de importancia, salvo algunas mermas cada cuatro a seis años o algún período seco cada diez (Popolizio, 1995).

\subsection{Suelos y erosión}

Los procesos de deterioro de los suelos a nivel provincial, causados por erosión hídrica y eólica. Ligier et al., (2015) destacan la erosión en surcos o cárcavas, que se produce por concentración de escurrimientos que socavan drásticamente el suelo. Las causas son similares a las anteriormente mencionadas, aunque exacerbadas por la pendiente, la erodabilidad del suelo y la intensidad de las lluvias. Se observa en la 
Altillanura fluvio-erosional, planicie aluvial del Paraná y Lomeríos del noreste (suelos rojos) y también la erosión en barrancos que provienen de procesos de oscilación reiterada del flujo hídrico de los ríos sobre materiales erodables (greda araucana o formación Toropí- Yupoí). Se agrava cuando se talan los bosques protectores o se elimina la vegetación herbácea. Impacta fuertemente en sectores urbanos, periurbanos y rurales vecinos al río.

La erosión de barrancos sobre el río Paraná (Figura 3) se evidencia principalmente desde la localidad de Empedrado hasta Lavalle, en el gran paisaje de la planicie aluvial del Paraná y sus afluentes.

Figura 3. Imagen de barrancas en Bella Vista.

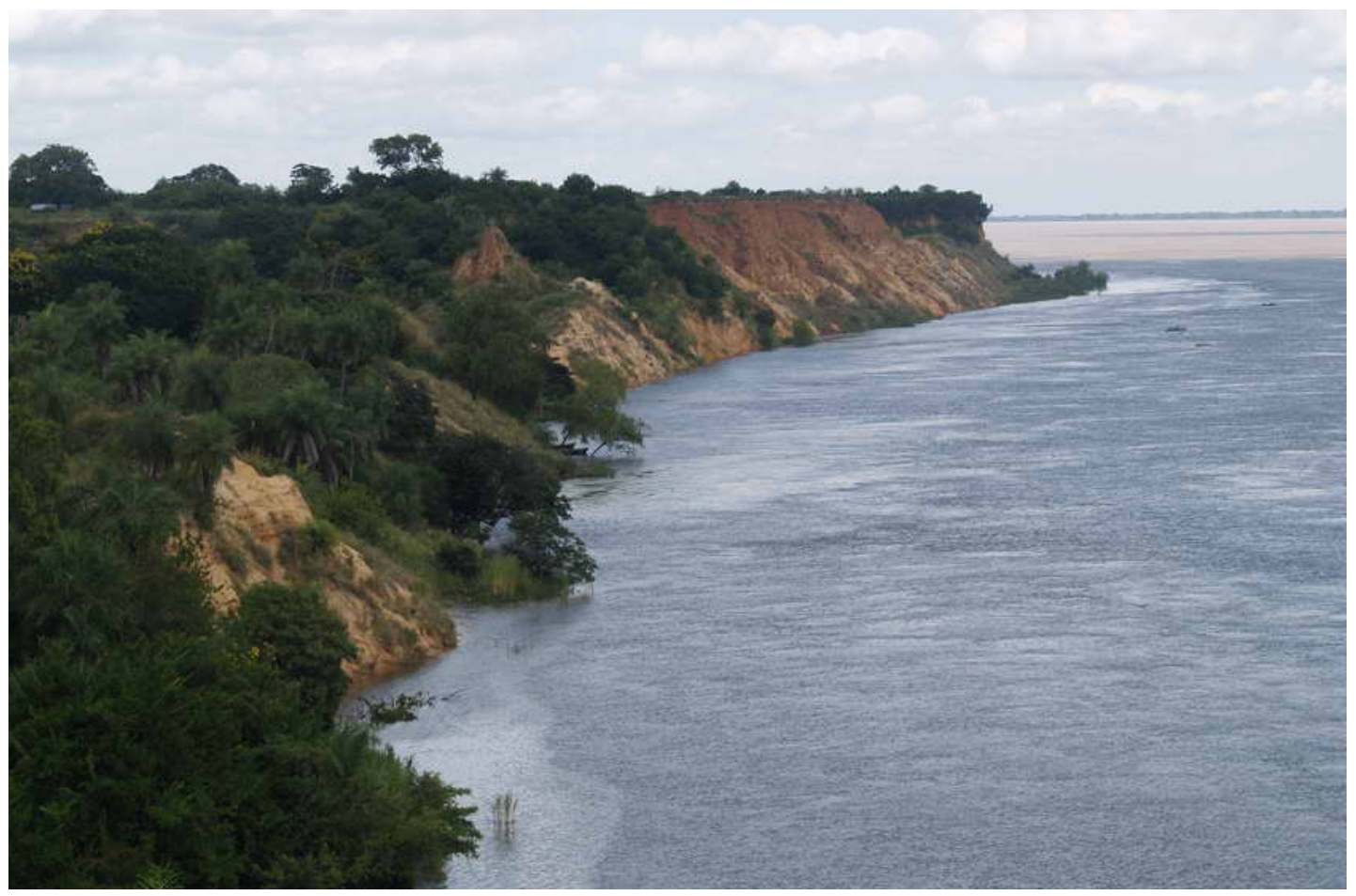

Fuente: www.bellavista.gob.ar

En el sector donde se originan las cárcavas, se pueden distinguir mayormente tres series de suelos más o menos bien diferenciadas (Gallardo et al., 1999).

Estos corresponden al sector de lomas arenosas rojas, cuyo material originario es de la formación Ituzaingó, arenas y areniscas, amarillentas, rosadas, rojizas y ocráceas con intercalación de pelitas grisáceas y gravillas. La fracción arena contiene cuarzo (99\%), en tanto que la arcilla compuesta principalmente por caolinita.

Las series de suelos que pueden encontrase en la zona de estudio e identificadas por (Escobar et al., 1996) se detallan a continuación:

\subsubsection{Lomas}

Suelo típico del Departamento de Bella Vista, ocupa 15.000 ha. Se localiza en relieve normal, posición de loma a media loma alta, con pendientes entre 1 y $1.5 \%$ La vegetación más común, presenta Digitariasp., Cynodonsp. y Sporobolussp., y está alterada por el uso agrícola. Son moderadamente bien drenados, con escurrimiento medio y permeabilidad moderada, sin peligro de anegamiento, muy susceptibles a la erosión eólica e hídrica.

El epipedón es ócrico, de $39 \mathrm{~cm}$. de espesor, arenoso a arenoso-franco, pardo claro a gris rosado en seco, sin estructura o solo de bloques débiles; continúa un horizonte BAt y luego un Btargílico, franco arenoso, con lamelas texturales, de color rojo amarillento, con escasos moteados y de reacción ácida. Es característica la presencia de un horizonte argílico, enterrado (Btb), que comienza a los $120 \mathrm{~cm}$. de profundidad, de textura franco arcillo-arenoso, rojizo, con estructura prismática y fuertemente ácido. La profundidad efectiva en estos suelos llega a los $120 \mathrm{~cm}$. Posee bajo contenido de materia orgánica, baja retención de humedad y escasa provisión de bases de cambio y capacidad de intercambio catiónico.

Presentan severas limitaciones, por alta susceptibilidad a erosión eólica e hídrica, baja fertilidad 
natural y baja retención de humedad; debido a sus buenas condiciones físicas relacionadas a la profundidad efectiva, son suelos aptos, en especial para cultivos perennes. El uso actual es frutícola (quintas cítricas), hortícola, forestal y como campo natural de pastoreo. El Indice de Productividad es 37 y la Capacidad de Uso es IIIes.

\subsubsection{Yataití Calle}

Cubre unas 9.000 ha. y participa también como suelo principal en la unidad 96, con 88.850 ha. Se ubica en relieve normal y en media loma alta, con pendientes que oscilan entre 1 a $3 \%$.

El tapiz vegetal está modificado por la agricultura y las especies más representativas son: Setareasp., Eragrostissp., Desmodiumsp., Phaseolussp., Arachissp., además de palmares de Butia yatay. Son algo excesivamente drenados, con escurrimiento medio y permeabilidad moderadamente rápida, sin peligro de anegamiento.

Presenta un epipedón ócrico espeso, arenoso, claro en seco y de estructura masiva. El horizonte Bw subyacente de $50 \mathrm{~cm}$. de espesor, es arenoso franco, pardo rojizo y fuertemente ácido, con lamelas texturales que le confieren el carácter álfico. A los $100 \mathrm{~cm}$. de profundidad, se define un horizonte argílico, enterrado (Btb), franco arcillo-arenoso, rojo a rojo oscuro. La profundidad efectiva de la Serie, sobrepasa los $120 \mathrm{~cm}$.

Estos suelos tienen excelentes condiciones físicas, para la exploración de las raíces y penetración del agua. No obstante, poseen escasa fertilidad natural, con muy bajos valores de bases de cambio en todo el perfil. El horizonte A, es pobre en materia orgánica y la retención de humedad tanto en el horizonte A1 como en el B2 es muy baja. Son aptos para cultivos perennes (citrus), forestales y cultivos horticolas, con manejo de riego y fertilización, coincidiendo con el uso actual. La Clase de

Capacidad de Uso es IIIes y el Índice de Productividad es de 29.

\subsubsection{Chavarría}

Cubre una superficie de 22.000 ha. y participa en las unidades $15,19,21,27,28,35,40,46,49,65$ y 96, con 380.300 ha., constituyéndo así una de las Series de suelos de mayor distribución y superficie dentro de la provincia. Se ubica en relieve normal, en posición de media loma a media loma baja, con pendientes de 1 a 1,5\%, en planicies arenosas pardo amarillentas. El tapiz vegetal está compuesto por pajonales de Andropogonlateralis, acompañado de Axonopussp, Schizachiriumsp., Sporobolussp. y otros de hábitos húmedos como ciperáceas y centella. El escurrimiento es lento a medio, la permeabilidad moderadamente lenta y el drenaje es imperfecto a moderado.

Presenta un horizonte ócrico, arenoso-franco, seguido de un Eb, álbico, de colores claros, arenoso, con abundantes moteados, sobrepuesto a un argílico, enterrado (Btbg), franco-arcillo-arenoso, de lenta permeabilidad. Se destaca un cambio textural abrupto entre ambos horizontes, que dificulta la entrada del agua, produciéndose una falsa napa de agua que fluctúa hasta cerca de la superficie, con movimientos laterales por el Ebg, ocasionando erosión subsuperficial. Esta napa freática generalmente está unida a numerosas lagunas circulares que existen en este ambiente. La profundidad efectiva generalmente es coincidente con el techo de la napa colgante $(50-60 \mathrm{~cm}$.).

Son suelos de muy baja fertilidad, con escaso tenor de materia orgánica, bajo contenido de bases de cambio y C.I.C (capacidad de intercambio catiónico), débilmente ácidos y de pobre retención de humedad en los horizontes superiores.

Presentan muy severas limitaciones que restringen la elección de plantas y requieren un manejo cuidadoso. Las principales limitantes se refieren al exceso de humedad con sobresaturación por tiempos prolongados, además de su baja fertilidad natural. El uso actual es la ganadería extensiva, no obstante, es utilizado para forestación y agricultura, con los consiguientes riesgos, si no se mejoran las condiciones de drenaje y fertilidad. Se ubica en la Clase IVw y el Î́ndice de Productividad es de 16.

Puede observarse en función de los tipos de suelos mencionados, que la clase de erosión posible o esperable es ligera y a menos que se cambien radicalmente las condiciones de las cárcavas existentes en el ejido municipal estas permanecerán inactiva o en equilibrio sin desarrollar actividad de retroceso degradante. El factor que podría romper este equilibrio es la eventual velocidad del agua que transite por la cárcava cuando se efectúen descargas, problema que se intensifica aún más cuando se retira la cubierta vegetal. 
Se comparó expeditivamente el retroceso que experimenta la cárcava situada en la intersección de la Av. De los Citricultores con el río Paraná (Figura 4), la comparación se hizo analizando dos imágenes de Google Earth de los años 2006 y 2013, la cárcava analizada corresponde al sector de desagüe pluvial de la zona sur de la localidad. En la Figura 4 puede verse que este retroceso está entre los 6 y $10 \mathrm{~m}$.

Figura 4. Vista aérea de cárcava y delimitación.

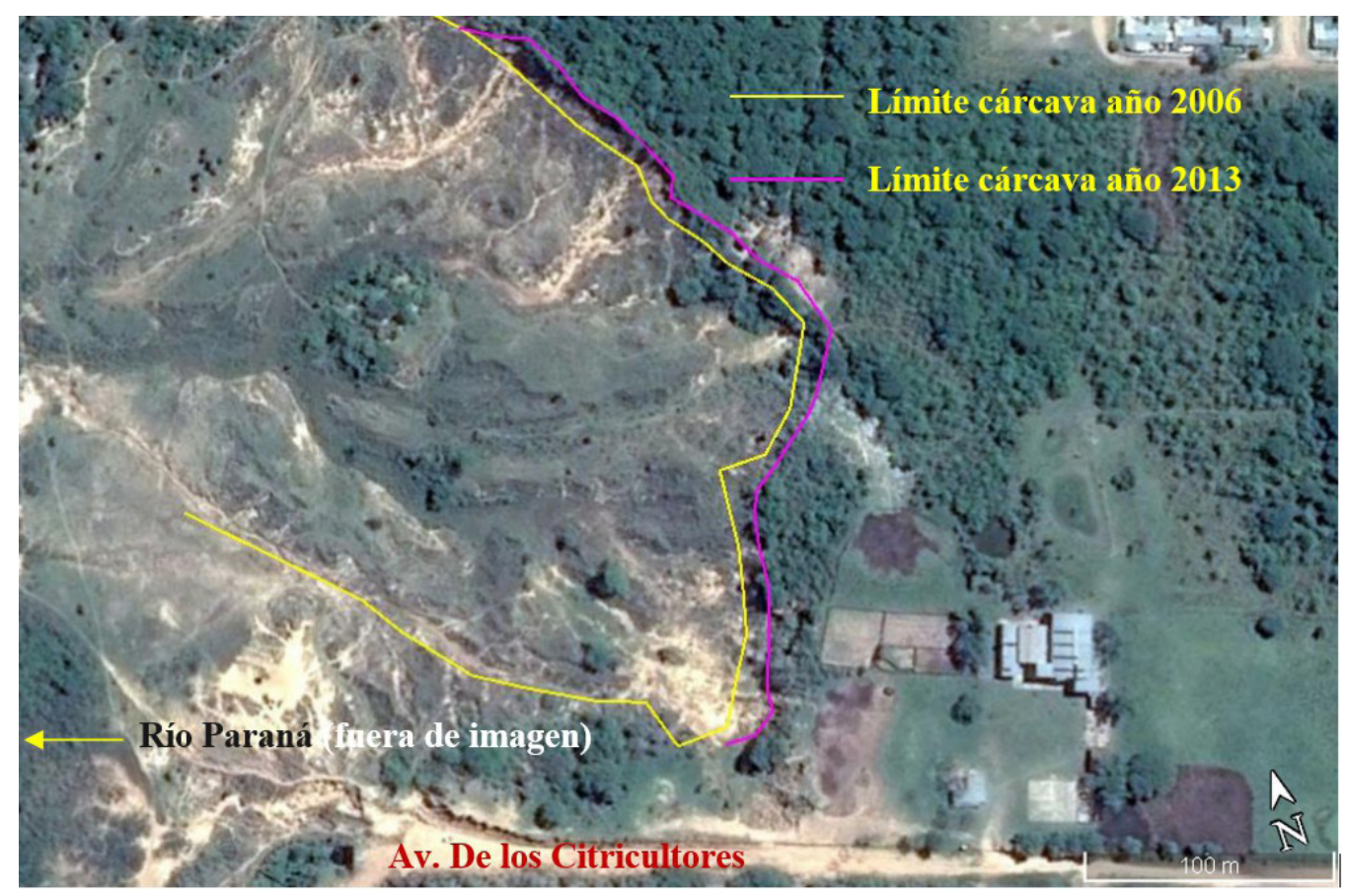

Fuente: Google Earth.

\subsection{Vegetación}

La vegetación en la localidad de Bella Vista del área de la cárcava es la típica de la terraza baja del río Paraná, sobre suelos arenosos, la fisonomía es el pastizal pseudoestépico de gramíneas estépicas, intermedias con arbustos (Gallardo, 1999).

Sepuedecaracterizaraestascárcavasdesdeelpuntodevistafitogeográficocomounasabanagraminosa disturbada de gramíneas de Andropogonlateralis, prado en pendiente de Paspalumnotatum y Axonopus compressus, también en partes se distinguen matas aisladas de Espartillares de Elyonurusmuticus. Así mismo en el talud de algunas cárcavas se observa presencia de Butia yatay y Copernciaaustralis (Palma) (Figura 5). Y también se hallan ejemplares aislados de Eugenia uniflora (ñangapirí). 
Figura 5. Aspecto y vegetación de la cárcava existente.

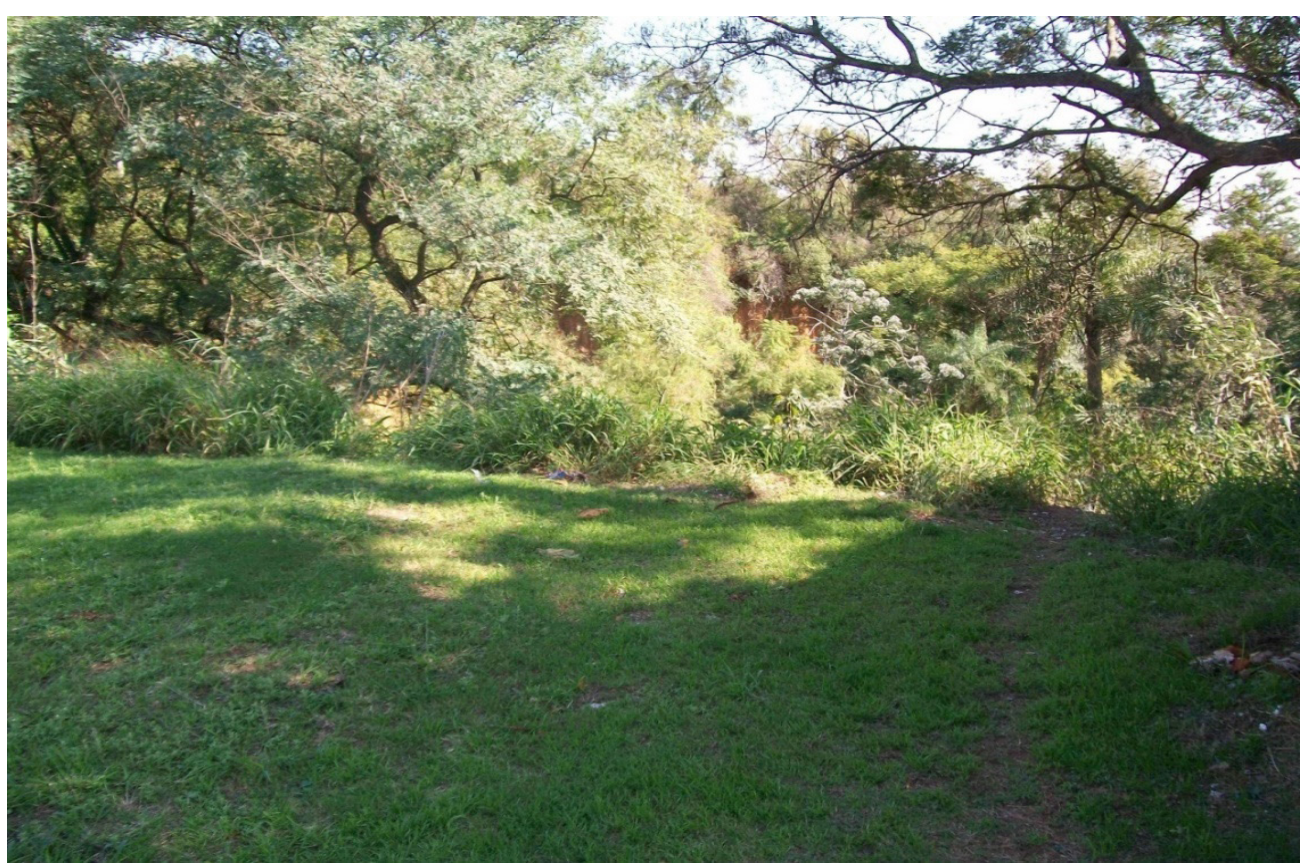

Fuente: Gómez, 2012.

\subsection{Análisis de proyectos y/o estudios en el área estudiada}

Se analizaron estudios y proyectos realizados para la localidad de Bella Vista, estos datan de los años 1997, 1999, 2012 y 2015. Todos contemplan, por la vulnerabilidad del sistema, medidas de mitigación del impacto que se puede generar por la acción producida por el escurrimiento superficial, en la zona de descargas de los excedentes pluviales.

La documentación analizada consistente en informes de consultoría, evaluaciones de impacto ambiental, pliego de licitaciones y documentación gráfica, como planos y esquemas de la zona, describen que se han tenido en cuenta medidas de atenuación del efecto erosivo de las aguas de escurrimiento superficial.

Estas medidas de atenuación consisten en medidas de tipo tecnológica, medida de atenuación agronómicas y medidas hidrológicas.

Entre las medidas de atenuación de tipo tecnológica, en estudios analizados se identifican obras de intervención directa en las zonas de descarga.

Se ha dispuesto en general en la zona de descarga: recubrimiento del canal de escurrimiento en el interior de la cárcava a la salida de los conductos. Este recubrimiento se hizo con colchonetas rellenas con piedra triturada, de no más de $20 \mathrm{~cm}$. de diámetro, contenidas en recipientes de alambre tejido romboidal galvanizado.

Se han interpuesto vallas de contención en forma transversal al curso de agua que pudieran transitar por la cárcava (Figura 6), presentando una escotadura central (que intervendrá como un vertedero) por la cual circulará el agua, reduciendo su velocidad y destinadas a inducir la acumulación de posibles sedimentos. 
Figura 6. Esquema de valla transversal de contención.

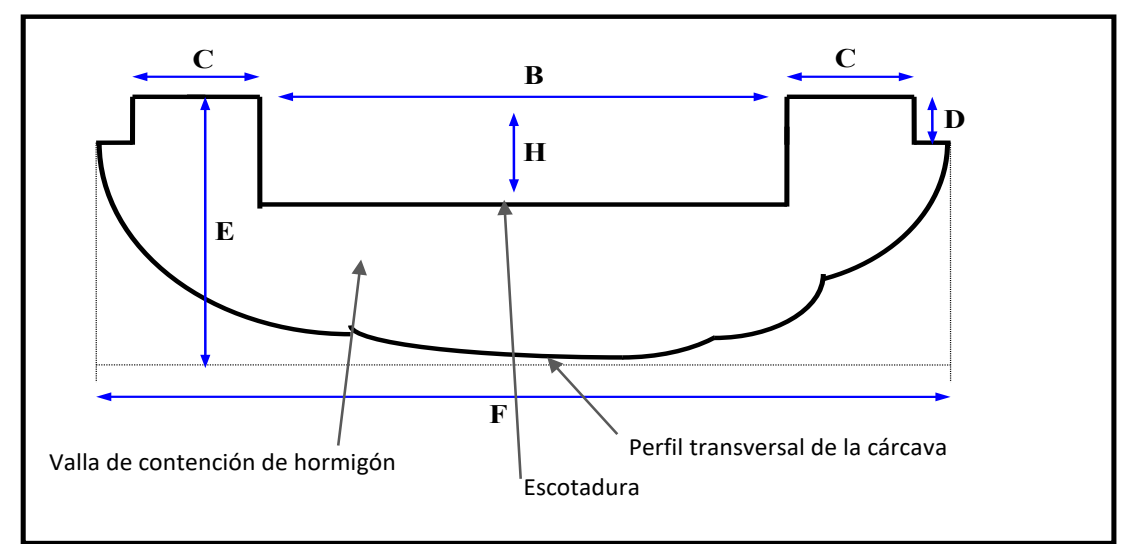

Fuente: Gallardo, 1999.

En otras descargas es posible observar que además de proteger con gaviones y/o colchonetas rellenas con piedra triturada, se ha fijado la atención en la energía que el agua trae en el escurrimiento, previendo la construcción de cuencos disipadores de energía por los elevados desniveles.

La presencia de un disipador de energía permite inferir que la transición entre la descarga y el medio natural hasta llegar al cuerpo de agua receptor (río Paraná) se hará una mínima alteración.

Entre las medidas de atenuación agronómicas se recomienda revestir las cárcavas de descarga, utilizando en lo posible vegetación natural de la zona, excluir la incorporación de especies que formen matas, espinosas u otras que eventualmente se conviertan en especies invasoras.

En el caso de no poder utilizar especies nativas se recomiendan el pasto Pangola(Digitariadecumbens) o el Pasto Jesuita (Axonopus compressus). No deben quedar superficies descubiertas, y por más pequeñas que sean deben tener protección vegetal. Emplear cortinas vegetales como estrategia, en razón que el viento suele provocar voladuras de vegetación dejando el suelo descubierto, que es afectado luego por correderas del agua.

Como medida de atenuación hidrológica el proyecto de drenajes pluviales de la ciudad de Bella Vista, recientemente, establece que es importante mantener los bajos que aún perduran ya que los mismos permiten la amortiguación de las crecidas (por lluvia) y un mejor funcionamiento del sistema proyectado.

Se plantea entonces un esquema en el que lagunas naturales existentes, bajos y reservorios artificiales debe preservarse y respetarse de manera que se logre la eficiencia hidrológica del sistema.

Clasificando los sistemas de acumulación en, sistemas permanentes que corresponden a las lagunas naturales que presentan un espejo de agua permanente o casi permanente y sistemas transitorios que corresponden a los bajos y reservorios artificiales de detención, que permanecen secos la mayor parte del tiempo y solo operan en coincidencia con eventos de cierta magnitud.

En lo referente a la obra de descarga de efluente cloacal tratado, HabitatConsult en 1997 expresa que no genera erosión en la zona de descarga, puesto que se ha proyectado un sistema de desagüe que ingresa directamente al río en forma sumergida.

\section{Conclusiones}

El empleo de disipadores de energía a la salida disminuirá el efecto erosivo de la escorrentía.

Usar cuerpos de aguas naturales y artificiales reducirá el volumen de escurrimiento directo y consecuentemente la velocidad de escurrimiento en las salidas del sistema geomorfológico.

Recubrir con vegetación acorde las cárcavas de salida, hará disminuir la velocidad del agua.

La implementación de medidas estructurales y no estructurales propende a mitigar los efectos producidos directa o indirectamente por las obras.

El profesional interviniente en una obra de ingeniería, primeramente, en la fase de proyecto y luego en la etapa de materialización, debe tener una observación permanente y aguda sobre la geomorfología del lugar y los problemas que se podrían generar, tratando de predecir el comportamiento de los sistemas 
naturales que responden a un sistema complejo y variable

Se analizó objetivamente el comportamiento del sistema geomorfológico por efecto del impacto ambiental que puede ocasionar respuestas no esperadas en el mismo.

\section{Referencias bibliográficas}

Breña Puyol A., Jacobo Villa M. (2006). Principios y fundamentos de la hidrología superficial. Universidad Autónoma Metropolitana, Tlalpan, D.F. México. http://cenca.imta.mx

Bruniard E. (1997). Atlas Geográfico de la Provincia de Corrientes. GEOGRÁFICA, 8, pp. 16-19.

Chow, V.T., Maidment, D. \& Mays, L. (1994). Hidrología aplicada. Santa Fe de Bogotá: Mc Graw-Hill.

Escobar, E; Ligier, H; Melgar, R; Matteio, H. Mapa de Suelos de la Provincia de Corrientes. (1996). INTA-Centro Regional Corrientes. EEA Corrientes.

Gallardo, H.; Ruberto A.; Sotelo C. y Currie H. (1999). Verificación de Parámetros, Estudios de Alternativas y Proyecto Ejecutivo para el Diseño de los Desagües Pluviales de los Barrios del IN.VI.CO. Bella Vista Corrientes. Programa Multisectorial de Preinversión II - UNPRE U.E.P. Corrientes.

Fotografía de Marcelo Gómez. (Bella Vista, 2012). Anteproyecto: Ampliación Sistema Cloacal de Bella Vista.

Habitat Consult. (1997). Evaluación de Impacto Ambiental: Proyecto Sistema Cloacal De Bella Vista-Provincia De Corrientes. ENoHSa. HabitatConsult S.R.L.

Ligier, D.; Perucca, A.y Kurtz, D. (2015). Erosión de suelos en la provincia de Corrientes. Avances La hoja informativa de la EEA Corrientes.

Popolizio, Eliseo. Geociencias Aplicadas a la Ingeniería, Arquitectura y Agrimensura. (1973). Geociencias I. Centro de Geociencias Aplicadas. UNNE.

Popolizio, E. (1977). Contribución a la geomorfología de la Provincia de Corrientes. Centro de Geociencias Aplicadas, UNNE, Resistencia, 7: 1-25.

Popolizio, Eliseo. Corrientes Taragüí. (1995). Bs As. Manrique ZagoEdiciones S.R.L.

Serra, P. (2001). Características Geomorfológicas E Hidrográficas de la Provincia de Corrientes y su Incidencia en Asentamientos Humanos. (Tesis doctoral). Universidad del Salvador, CABA. Recuperado de: https:/| racimo.usal.edu.ar/4243/

Strahler Arthur. (1974). Geografía Física. Barcelona. Ediciones Omega S.A.

Torres, Francisco. (1954). Informe geológico de la hoja de Goya. Bs. As. Ministerio de Guerra República Argentina

Provincia de Corrientes. (2016). Licitación Pública № 01/2016 - Drenajes Pluviales de la Ciudad de Bella Vista. Ministerio de Hacienda y Finanzas. Sub Unidad ejecutora Provincial. Recuperado de: www. corrientes.gov.ar 